\title{
microRNA and Cancer
}

\author{
Mengfeng Li, ${ }^{1,2,5}$ Jun Li, ${ }^{1,3}$ Xiaofan Ding, ${ }^{1,3}$ Mian He, ${ }^{1,2}$ and Shi-Yuan Cheng ${ }^{4}$
}

Received 20 August 2009; accepted 20 November 2009; published online 28 April 2010

\begin{abstract}
MicroRNAs (miRNAs), a class of small, regulatory, non-coding RNA molecules, display aberrant expression patterns and functional abnormalities in human diseases including cancers. This review summarizes the abnormally expressed miRNAs in various types of human cancers, possible mechanisms underlying such abnormalities, and miRNA-modulated molecular pathways critical for cancer development. Practical implications of miRNAs as biomarkers, novel drug targets and therapeutic tools for diagnosis, prognosis, and treatments of human cancers are also discussed.
\end{abstract}

KEY WORDS: biomarker; cancer; drug discovery; drug target; microRNA.

\section{INTRODUCTION}

MicroRNAs (miRNAs) are small, endogenous noncoding RNA molecules that contribute to modulating the expression level of specific proteins based on sequence complementarities with their target mRNA molecules . Most of miRNA species identified thus far are encoded in portions of the genome that had been previously thought to be noncoding regions. Since first discovered in 1993, miRNAs have attracted wide attention due to their unique functional significance and modes of action, providing a new dimension of, and the latest addendum to, the central dogma of molecular biology. Because one miRNA can target multiple mRNA targets, it is estimated that more than one third of human genes are regulated by miRNAs, and the number of genes found to be under the modulation of miRNAs has increased sharply. The role of miRNAs as key regulatory molecules that control a wide variety of fundamental cellular processes, such as proliferation, death, differentiation, motility, invasiveness, etc., is increasingly recognized in almost all fields of biological and biomedical fields.

Understanding the significance of miRNAs in the pathogenesis of human diseases represents an important dimension in miRNA research as it may lead to the development of

\footnotetext{
$\overline{{ }^{1} \text { Key Laboratory of Tropical Disease Control (Sun Yat-sen University), }}$ Ministry of Education, 74 Zhongshan Road II, Guangzhou, 510080, China.

${ }^{2}$ Department of Microbiology, Zhongshan School of Medicine, Sun Yat-sen University, 74 Zhongshan Road II, Guangzhou, Guangdong 510080, China.

${ }^{3}$ Department of Biochemistry, Zhongshan School of Medicine, Sun Yat-sen University, 74 Zhongshan Road II, Guangzhou, 510080, China.

${ }^{4}$ Cancer Institute and Departments of Pathology and Medicine, University of Pittsburgh, Pittsburgh, Pennsylvania 15213, USA.

${ }^{5}$ To whom correspondence should be addressed. (e-mail: limf@mail. sysu.edu.cn)
}

miRNA-based novel therapeutic strategies or diagnostic/ prognostic biomarkers. Among diseases that most seriously threaten human lives, cancer, which has been found by recent studies to be associated with deregulation or genetic changes of miRNAs as previously reviewed by others $(1,2)$, apparently represents an outstanding public health problem that causes 7.6 million deaths annually as estimated by WHO. This review attempts to briefly outline our current knowledge on the abnormalities of miRNAs found to be associated with cancer pathogenesis and possible mechanisms underlying the roles of miRNAs in cancer development and progression and to provide a perspective insight in using miRNAs as cancer biomarkers and therapeutic targets or tools.

\section{MIRNAS AND THEIR BIOLOGICAL FUNCTIONS}

miRNAs, a class of 21- to 24-nucleotides (nt), noncoding, regulatory RNA molecules, was first discovered in developing nematode (3). Up to date, thousands of miRNAs have been identified in a wide variety of species. Over 10,883 miRNA sequences found in animals, plants, and viruses have been published in the miRBase database, including 721 entries from human and 579 from mouse (http://microrna. sanger.ac.uk; Release 14: September 2009). With the number of identified miRNA increasing rapidly, rules of annotation have been suggested to designate individual miRNAs, such as hsa-miR-199, with "hsa" standing for the homo sapiens, "miR" for microRNA, and the number "199" indicating the order of being discovered.

miRNA coding sequences can be found in introns or exons of a protein-coding gene or in the intergenic regions. It is quite common that several miRNA genes are clustered along the genome, sharing the same promoter, whereas they can also be present individually. miRNA genes are transcribed into a large, non-coding messenger RNA strand known as primary miRNA transcript (pri-miRNA), with 
coding capacity for one or more mature miRNAs. PrimiRNA is subsequently processed into smaller, stem-looped, hairpin-like miRNA precursors (pre-miRNAs) of $\sim 70 \mathrm{nt}$ in length by RNase III-type enzyme Drosha that forms a microprocessor complex with the double-stranded RNAbinding protein DGCR8. Afterwards, pre-miRNAs are exported from the nucleus across the nuclear membrane into the cytoplasm through an Exportin-5/Ran complex. Similar to the processing of an siRNA, a pre-miRNA is then cleaved by a highly conserved RNase III-type enzyme Dicer to generate a 19- to 23-nt RNA duplex and then incorporated into a RISC-like ribonucleoprotein complex (RNP), also known as microRNA-induced silencing complex (miRISC) or miRNP. Only one strand of the miRNA, known as the guide strand, is integrated into miRISC, while the other strand, miRNA*, also known as the anti-guide or passenger strand, is degraded by the RISC. Although the biosynthesis of most miRNAs is through the Drosha pathway, recent findings suggest the existence of an alternative Drosha-independent pathway. For example, in Drosophila or Caenorhabditis elegance, premiRNAs in intronic sequences are produced without Drosha-mediated cleavage. miRNAs that are generated through this pathway are mirtrons that may still function similarly to a regular miRNA [for a review, see (4)].

The miRNA strand guides the RISC to its target mRNA, subsequently cleaving or silencing the target mRNA. While it was thought that miRNA represses the expression of their targets by inducing deadenylation and destabilization of mRNA, recent evidence suggests that the repressive function of miRNA is mediated through preventing translation from the target mRNA (5). Although the precise mechanism of such inhibitory effect on translation remains to be validated, it is believed that miRNA interferes with protein factors involved in the elongation process during translation (6). It has been proposed that the degree of complementarity between miRNA and its target mRNA is a crucial factor on which the mode of miRNA function is determined, with the miRNAs imperfectly complementary to the binding sites in the $3^{\prime}$ untranslated regions (UTR) of their target mRNA repressing the protein expression through translational inhibition, whereas those miRNAs perfectly or nearly perfectly complementary to mRNA targets inducing mRNA degradation through the RNA-mediated interference pathway [reviewed in (4)]. On the other hand, a cytosolic site called "P-body" has been proposed as dynamic foci for mRNA sequestration leading to translational repression and mRNA turnover. Several studies have demonstrated that Ago1 and Ago2 are localized to mammalian P-bodies, indicating a functional link between P-bodies and a miRNA-induced repression (7).

Interestingly, recent studies have suggested that a number of miRNAs are able to activate the expression of certain target genes in a sequence-specific manner instead of silencing them. For instance, miR-373 induces expression of E-cadherin and cold-shock domain-containing protein $\mathrm{C} 2$ (CSDC2) genes with complementary sequences in their promoters (8). This novel phenomenon, although largely remaining uncharacterized, is termed "RNA activation" (RNAa). While thus far the exact mechanisms of RNAa remain to be elucidated, the process may require the Ago2 protein and could be associated with histone changes linked to gene activation (9).
It is estimated that over $30 \%$ of protein-coding genes in human genome are regulated by miRNAs, suggesting that most of individual miRNAs target multiple protein-coding genes (10). Therefore, it is convincible that miRNAs play important roles in a wide variety of biological processes. Indeed, accumulated evidence has demonstrated modulation effects of miRNA on development, cell proliferation, differentiation, apoptosis, adhesion, migration and invasion, as well as other biological processes. Thus, expression of this important class of molecules is usually correlated with an array of pathological conditions, among which cancer may represent one of the most relevant diseases related to aberrant expression and/or functions of miRNAs.

\section{ABERRANT EXPRESSION OF MIRNAS IN CANCER}

The significance of miRNA in human cancers began to be revealed in 2002 when Croce and colleagues identified that a small genomic region in chromosome 13q14 that is commonly deleted in chronic lymphocytic leukemia (CLL) contained miR15a and miR-16-1 genes, suggesting a link of these miRNAs to CLL (11). Following this observation, more and more miRNAs have been found to be aberrantly expressed in various types of cancer cell lines and clinical tumor specimens. In addition to the identified abnormal levels of specific miRNAs in certain types of human cancers, biological evidence that suggests an important role of miRNAs in cancer development and progression was also experimentally demonstrated in animal models (12). To date, a spectrum of cancer-associated miRNAs has been identified. While some miRNAs function as tumor suppressors and are downregulated in cancer cells, other miRNAs act as oncogenes, inducing or promoting cancer development or progression. In this context, a number of miRNAs could play an oncogenic role in one setting but suppress tumor formation in a different scenario (13).

Abnormal expression profiles of miRNAs have been found in both clinical tumor specimens and cancer cell lines when compared with chosen normal controls by microarray, Northern blotting, or real-time RT-PCR analyses. In some types of cancers, global deregulation of miRNAs has been found, indicating that miRNAs have a general potential to target genes involved in cell proliferation, apoptosis, differentiation, invasiveness, and motility that are critical for development or progression of human cancers (14). Examples of the miRNAs that are aberrantly expressed in tissue-specific cancers are summarized in Table I.

\section{MIRNA MODULATION OF TUMOR SUPPRESSOR AND ONCOGENIC PATHWAYS}

A number of oncogenic pathways have been found to be under the modulation of miRNAs. As aforementioned, because an individual miRNA usually targets multiple genes that are involved in various cellular signaling pathways, aberrant expression or malfunction of a miRNA could exhibit powerful capability in oncogenesis. The retinoblastoma $(\mathrm{pRb})$ pathway represents one of regulatory networks frequently altered in cancer cells. $\mathrm{pRb}$ is a tumor suppressor that associates with and inhibits transcription factors of the E2F family, causing cell cycle arrest. On the other hand, $\mathrm{pRb}$ is inactivated through protein phosphorylation by cell cycle- 
Table I. miRNAs Aberrantly Expressed in Cancers

\begin{tabular}{|c|c|c|c|}
\hline Cancer type & Upregulated & Downregulated & Reference \\
\hline Breast cancer & $\begin{array}{l}\text { miR-10b, miR-21, miR-22, miR-27a, } \\
\text { miR-155, miR-210, miR-221, miR-222, } \\
\text { miR-328, miR-373, miR-520c }\end{array}$ & $\begin{array}{l}\text { let-7, miR-7, miR-9-1, miR-17/miR-20, miR-31, } \\
\text { miR-125a, miR-125b, miR-146, miR-200 family, } \\
\text { miR-205, miR-206, miR-335 }\end{array}$ & $(15-31)$ \\
\hline CLL & miR-21,miR-155 & $\begin{array}{l}\text { miR-15, miR-16, miR-29b, miR-29c, miR-34a, } \\
\text { miR-143, miR-145, miR-181b, miR-223 }\end{array}$ & $(11,32-36)$ \\
\hline Lung cancer & $\begin{array}{l}\text { miR-17-92 cluster, miR-21, miR-106a, } \\
\text { miR-155 }\end{array}$ & $\begin{array}{l}\text { miR-1, let-7 family, miR-7, miR-15a/miR-16, } \\
\text { miR-29 family }\end{array}$ & $(12,22,37-40)$ \\
\hline Lymphoma & miR-17-92 cluster, miR-155 & miR-143, miR-145 & $(36,41,42)$ \\
\hline Prostate cancer & miR-221, miR-222 & $\begin{array}{l}\text { miR-15a-miR-16-1 cluster, miR-101, miR-127, } \\
\text { miR-449a }\end{array}$ & $(43-47)$ \\
\hline Glioblastoma & miR-21, miR-221, miR-222 & $\operatorname{miR}-7$ & $(22,48,49)$ \\
\hline Hepatocellular carcinoma & $\begin{array}{l}\text { miR-17-92 cluster, miR-21, miR-143, } \\
\text { miR-224 }\end{array}$ & miR-1, miR-101, miR-122a & $(50-55)$ \\
\hline Colorectal cancer & miR-17-92 cluster, miR-21 & $\begin{array}{l}\text { miR-34a, } \mathrm{miR}-34 \mathrm{~b} / \mathrm{c}, \mathrm{miR}-127, \mathrm{miR}-143 \\
\mathrm{miR}-145, \mathrm{miR}-342\end{array}$ & $(46,56-60)$ \\
\hline Gastric cancer & $\operatorname{miR}-21, \operatorname{miR}-27 \mathrm{a}$ & miR-143, miR-145 & $(61-63)$ \\
\hline Ovarian cancer & $\operatorname{miR}-214$ & miR-34b/c, miR-200 family & $(64-66)$ \\
\hline Melanoma & miR-221, miR-222 & let-7a, miR-34a & $(67-69)$ \\
\hline $\begin{array}{l}\text { Head and neck squamous } \\
\text { cell carcinoma }\end{array}$ & $\operatorname{miR}-21$ & let-7d, miR-138, miR-205 & $(70-72)$ \\
\hline
\end{tabular}

$C L L$ chronic lymphocytic leukemia, $C N V$ copy number variation, $C S D C 2$ cold-shock domain-containing protein $C 2, E B V$ Epstein-Barr virus, $E M T$ epithelial-to-mesenchymal transformation, EZH2 enhancer of zeste homolog 2, $H B V$ hepatitis B virus, $L N A$ locked nucleic acid, miRISC microRNA-induced silencing complex, miRNA microRNA, miRNP microRNA-induced silencing complex, $N P C$ nasopharyngeal carcinoma, $N S C L C$ non-small-cell lung carcinoma, $n t$ nucleotides, $p 53 R E$ p53 response element, $p R b$ retinoblastoma protein, pre-miRNA miRNA precursor, pri-miRNA primary miRNA transcript, $P T C$ papillary thyroid carcinoma, $R N A a$ RNA activation, $R N P$ RISC-like ribonucleoprotein complex, $S N P$ single nucleotide polymorphisms, TARBP2 TAR RNA-binding protein 2, UTR untranslated region

dependent kinases such as Cdk2 and Cyclin E, which are also negatively regulated by cell cycle inhibitors of members of INK4 or Cip/Kip families such as p16, p11, and p27. Accumulating evidence suggests that miRNAs modulate the $\mathrm{pRb}$ pathway at almost all levels. $3^{\prime}$-UTR of the $\mathrm{pRb}$ gene can interact with and be suppressed by miR-106a, which is overexpressed in various types of human cancers, and such an inhibitory effect of miR-106a is associated with downregulation of the $\mathrm{pRb}$ protein (37). Moreover, E2F is downregulated by the miR-17-92 cluster (73), whereas miR-34a that could be induced by p53 suppresses the expression of cyclin D1 and CDK6 (74). Similarly, miR-192 and miR-215 that also are induced by p53 can enhance the accumulation of p21 and induce cell cycle arrest in colon cancer cells (75). Additionally, CDK6 is suppressed by miR-124 or miR-137 that are often inactivated by epigenetic changes in tumor cells (76). Furthermore, oncogenic cyclin D1 is a target of miR-17/20 that is frequently downregulated in breast cancers (77). Taken together, miRNAs have complicated the molecular networks that control the cell cycle and proliferation by adding another dimension of regulation, and yet from the evolutionary point of view, such a multi-dimension and multilayer regulatory mechanism provides more powerful and precise maintenance over the stability and efficacy of these critical pathways.

Oncogene Myc plays crucial roles in modulating cell proliferation through its proliferation-promoting function via E2F, Cdk2, and cdc25 (78) and induces cell apoptosis through upregulation of an apoptosis inducer, Bim (79). On one hand, Myc is regulated by miRNAs, including miR-145 and miR-34 $(80,81)$; on the other hand, Myc induces transcription of miRNAs such as the miR-106b-25 cluster and the miR-17-92 cluster (73). Interestingly, some of the miRNAs in the above clusters inhibit the expression of Bim and E2F $(73,82)$. Thus, the biological impact by miRNA-associated Myc modulation is complicated and can be bidirectional. Whether the net outcome of such modulatory mechanisms is oncogenic or tumor-suppressing is context-dependent in different microenvironments.

It was found that miR-29a, miR-29b, and miR-29c could directly suppress $\mathrm{p} 85$, the regulatory subunit of PI3K, and CDC42, a Rho family GTPase, both of which negatively regulate $\mathrm{p} 53$. Thus, the miR-29 family members could induce p53-dependent cell apoptosis (83). On the other hand, the miR34 family members are direct targets for p53 (66). Low expression of miR-34a in CLL is associated with p53 inactivation, and p53-induced cell apoptosis could be dramatically attenuated by inactivation of miR-34a in cells exposed to genotoxic stress, whereas mildly increased by overexpressing miR-34a (84). Furthermore, miR-34a could also downregulate SIRT1, leading to an increase in acetylation of p53 and expression of p21 and PUMA that are transcription targets of p53 (85). miR-145 is another p53-induced miRNA and has a potential $\mathrm{p} 53$ response element (p53RE) in its promoter region. Interestingly, miR-145 also directly downregulates c-myc, thus linking the p53 pathway to the c-myc pathway (80).

Another interesting aspect of cancer-associated miRNAs is their roles in virus-induced human cancers. Numerous types of human cancer-associated viruses have been found to express miRNAs. Epstein-Barr virus (EBV), a herpesvirus associated with Burkitt's lymphoma and nasopharyngeal carcinoma, expresses multiple miRNA species. One of EBVcoded miRNAs, miR-BART5, downregulates PUMA, contributing to increased host cell survival and establishment of latent infection of the virus (86). Using computation-assisted 
approaches, a candidate pre-miRNAs was identified in HBV. By searching the $3^{\prime}$ UTR sequences of human genome, a large number of cellular transcripts were predicted as potential targets of viral miRNAs, and these predicted miRNAs, if validated, could play important roles in virus infection (87).

\section{MIRNAS IN TUMOR ANGIOGENESIS AND METASTASIS}

It is widely accepted that growth and dissemination of tumors require the development of neovasculature, a key process known as angiogenesis. Possible roles of miRNAs in angiogenic response of tumors have been recently demonstrated. miR-126 that is abundantly expressed in endothelial cells plays an important role in vascular development in mice and zebrafish. miR-126 enhances the pro-angiogenic effects of VEGF and FGF by directly targeting Spred-1, a negative regulator of the VEGF and FGF signaling pathways (88). Other miRNAs such as miR-130a and miR-296 are also involved in tumor angiogenesis through modulation of the expression of pro-angiogenic receptors and antiangiogenic factors such as HGS, GAX, and HOXA5, respectively $(89,90)$.

A vast majority of cancer deaths are caused by metastasis. When metastasis occurs, the polarized immotile epithelial cells transform into motile mesenchymal cells, a phenomenon known as epithelial-to-mesenchymal transformation (EMT). Accumulating evidence shows that TGF- $\beta$ and ZEB take important parts in the EMT process, characterized by high-level expression of transcription factors that bind to the E-Box of promoter regions in genes of E-cadherin and other polarity proteins, and repress their gene expression. In this context, miR-200 represses both TGF- $\beta$ and ZEB, contributing to the maintenance of the epithelial phenotype of cancer cells (91). Loss of expression of members of the miR-200 family in several types of cancers such as ovarian cancers and breast cancers enhances the tumor metastasis by downregulating E-cadherin and promoting EMT during cancer progression $(16,64)$. Additionally, correlations of other miRNAs with cancer metastasis have also been reported. For example, miR-10b and miR-373 were found to promote breast cancer invasion and metastasis, respectively $(30,31)$. Regulation of cell survival and metastasis by miRNAs could also be mediated through the repression of histone methyltransferase. Enhancer of zeste homolog 2 (EZH2) is a mammalian histone methyltransferase that involves the epigenetic silencing of genes and cancer cell survival and metastasis. EZH2 is overexpressed in aggressive solid tumors such as prostate cancer, and miR-101 inhibits the expression of $\mathrm{EZH} 2$ in cancer cell lines (47). Thus, in addition to specifically targeting one or more signaling pathways, aberrantly expressed miRNAs also modulate the overall epigenetic status of the genome, leading to a global change in the expression profiles that consequently effect on initiation, progression, and metastasis of human cancers (47).

Taken together, it is evident that miRNAs regulate the expression of proteins involved in a wide variety of signaling pathways critical for cancer development and progression. Some of the miRNA-targeted proteins connect to different cellular signaling networks. Fully understanding the role of miRNAs in modulating the expression and functions of these pathway connector proteins will significantly advance our knowledge of the biology of human cancers. Possible roles of miRNA in development and progression of cancer are illustrated in Fig. 1.

\section{CAUSES OF ABERRANT MIRNA EXPRESSION IN CANCERS}

\section{SNP and Mutations in pri-miRNA Sequence}

Single nucleotide polymorphism (SNP) and mutations in pri-miRNAs sequences could significantly alter the secondary structure of pre-miRNA, which subsequently affects the binding affinity between miRNA and mRNA. For example, the rs11614913 SNP in miR-196a-2 gene is associated with the survival probability of individuals suffering from non-small-cell lung carcinoma (NSCLC). In a genotype-phenotype correlation analysis of 23 human lung cancer specimens, rs11614913 CC was found to be associated with a statistically significant increase in the expression of mature miR-196a. The survival of patients with lung cancers was significantly decreased in individuals who carried homozygous CC at rs11614913, suggesting that the rs11614913 SNP might be a useful prognostic biomarker for NSCLC (92).

A G/C polymorphism (rs2910164) within the pre-miR146a coding sequence is frequently found in papillary thyroid carcinoma (PTC). When compared with that from the G allele, the production of pre- and mature miR-146a from the $\mathrm{C}$ allele is reduced by $1.9-$ and 1.8 -fold, respectively, possibly due to impeded binding of a nuclear factor to $\mathrm{C}$ allele-derived pre-miR-146a, which leads to reduced production of a mature miRNA. Reduced miR-146a production results in lowered efficiency in inhibiting target genes involved in the Toll-like receptor-mediated cytokine signaling and PTC1, a gene

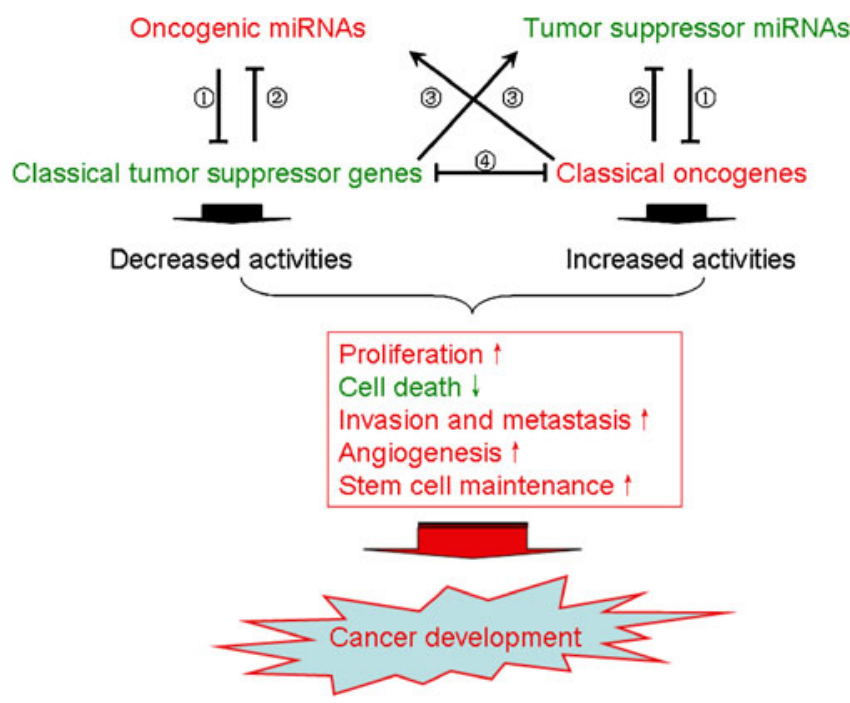

Fig. 1. Functions of miRNA in cancer development and progression. Possible interactions among oncogenic and tumor suppressor miRNAs and classical genes and consequences in cancer development are illustrated. Green color, downregulated or attenuated. Red color, upregulated or enhanced. (1) Translation inhibition/mRNA degradation; (2) Transcriptional inhibition (direct or indirect); (3) Transcriptional activation (direct or indirect); (4) Transcriptional inhibition/ activity inhibition 
frequently rearranged with the RET proto-oncogene in PTC, increasing the risk of acquiring PTC (93). Heterozygosity for polymorphisms within a pre-miR sequence can also cause epistatic gene regulation due to the production of another mature miRNA derived from the passenger strand. Jazdzewski $\mathrm{K}$ et al. reported that miR-146a GC heterozygotes are different from both the $\mathrm{GG}$ and $\mathrm{CC}$ homozygotes in their abilities to produce three mature miRNAs, namely, one from the leading strand (miR-146a) and two from the passenger strand (miR-146a*G and miR$\left.146 \mathrm{a}^{*} \mathrm{C}\right)$, each having a distinct target set. Analysis of paired tumor/normal samples showed a 0.5- to 2.6-fold upregulation of polymorphic miR-146a* in seven of eight PTC tumors tested when compared with the unaffected regions of the thyroid. Microarray data showed differential profile of transcriptomes distinct between patients of GC and GG genotypes. A majority of the altered genes are apoptosis regulators, suggesting a potential cause for the changed risk of acquiring thyroid cancer (94).

Recently, germline or somatic mutations of miRNA genes have been identified in clinical specimens of CLL and several types of solid tumors. Sequencing analysis of 75 CLL patients revealed mutations in 5 of 42 miRNA genes examined. Two of $75 \mathrm{CLL}$ patients were found to carry mutations in primary miR-16-1 and miR-15a sequences with $\mathrm{C}$ to $\mathrm{T}$ mutations. This mutation was associated with lower expression of the mature miR-16-1 and miR-15a (95). In solid tumors, 15 cancer-associated miRNAs were analyzed in 91 cancer-derived cell lines, leading to the identification of one variation in a miRNA precursor and 15 variations in primary miRNAs (96).

\section{Copy Number Ateration}

Alteration in copy number of miRNA coding cassettes gives rise to copy number variation $(\mathrm{CNV})$ in cells. CNV usually involves gains or losses of large segments of DNA sequence consisting of thousands to millions of nucleotides, leading to significant changes of expression level of miRNAs (for collections of CNVs, see http://www.sanger.ac.uk/humgen/cnv).

Calin et al. (97) mapped the genomic locations of 186 miRNAs and compared them with previously reported nonrandom genetic alterations. The study found that miRNA genes were frequently located at fragile sites of the genome, as well as in minimal regions of loss of heterozygosity, minimal regions of amplification (minimal amplicons), or common breakpoint regions. Overall, $52.5 \%$ of miRNA genes were in cancerassociated genomic regions or in fragile sites, and numerous miRNAs located in the deleted regions exhibited low levels of expression in cancer samples, suggesting important roles of CNV-induced alteration of miRNA expression in cancers (97). Additionally, the overall involvement of miRNA genes in CNV regions can be revealed by a genome-wide analysis (98).

Loss of chromosomal segments on chromosome 13 at cytoband 13q14, a most frequent genetic alteration in CLL, includes genotypic subtypes among which the type Ia deletions are relatively uniform in length $(50.2-50.5 \mathrm{Mb})$ and commonly involve the miR $15 \mathrm{a} / \mathrm{miR} 16$ gene cluster. Deletion of miR-16-1 and miR-15a at 13q14 was found in over $15 \%$ of CLL patients. Due to the suppressive effect of both miRNAs on Bcl-2 expression, their deletion and consequent loss of expression might contribute to the development of CLL (99).

\section{Abnormal Transcription}

Recent expression profiling of miRNAs in human cancers showed an overall downregulation of miRNAs. Molecular mechanisms that account for such inhibition include failure of miRNA posttranscriptional regulation, transcriptional silencing associated with epigenetic changes, transcriptional repression by dysfunction of transcription factors, and defects in the miRNA biogenesis that involves enzymes and cofactors important for miRNA processing. For instance, in ovarian cancers, the level of total mature miRNAs was reduced and closely associated with a lowered level of Dicer protein. At the transcriptional level, global sequence analysis revealed that over $46 \%$ of 326 miRNA putative promoters contained potential p53 binding sites, and downregulation of wild-type p53 via specific siRNAs abolished the effect of wt-p53 in regulating miRNAs in HCT-116 colon cancer cells (100).

Protein TARBP2 (TAR RNA-binding protein 2), an integral component of a DICER1-containing complex, was found to have frame shift mutations in sporadic and hereditary carcinomas with microsatellite instability. This might result in a decrease in TRBP protein expression and a defect in the processing of miRNAs because reintroduction of TRBP in TRBP-deficient cells restored an efficient production of mature miRNAs and inhibited tumor growth (101).

Global upregulation of miRNA also has been found in certain types of human cancers. For example, microarray analysis of metastatic prostate adenocarcinomas in comparison with normal prostate tissues showed an upregulation of major components of the machinery for miRNA processing including Dicer. Importantly, increased expression of these proteins is associated with a global increase in miRNA expression and progression of clinical stage of prostate adenocarcinoma (102).

\section{MIRNAS AS BIOMARKERS FOR CANCER DIAGNOSIS}

Distinguishable abnormalities in miRNA genes and expression patterns are being identified continuously in almost all types of cancer, thus providing a strong rationale for the application of miRNAs as diagnostic/prognostic biomarkers. Expression profiles of miRNAs have been found significantly altered in numerous types of human cancers when compared with their corresponding normal tissues, among different subtypes within the same type of cancers, or among individual patients suffering from a same type of cancer but having different prognoses. For example, miR-21 is expressed at high levels in glioblastoma as opposed to a low basal level in normal brain tissues, establishing miR-21 as a potential diagnostic marker for glioblastoma (48). In lung cancers, expression profiles of miRNAs correlate with the survival of patients with lung adenocarcinomas including those with stage I disease. High levels of miR-155 and low levels of let-7a-2 expression are associated with poorer patient survival (103). In breast cancers, overexpression of miR-21 correlates with certain pathophysiological features of the disease such as advanced tumor stage, lymph node 
metastasis, and poor survival of the patients (104). A study using microarray on 435 mature human miRNA oligonucleotide probes identifies miR-21 as a potential prognostic marker for diagnosis of breast cancers (104). Moreover, expression of miR-210 in breast cancer specimens reveals an inverse correlation with disease-free and overall survival, suggesting that miR-210 could be another independent prognostic factor for breast cancers (25). Additionally, miRNA signature might also be useful to distinguish different subtypes of human cancers. Comparative analysis on the expression patterns of miRNAs in 122 adenocarcinoma versus squamous lung cancer samples identified miR-205 as a highly specific marker for squamous cell lung carcinoma, with a sensitivity of $96 \%$ and a specificity of $90 \%$ (105).

It is noteworthy that miRNAs can be often found in the circulation and in microvesicles (also known as exosome when produced by tumor tissues) in the peripheral blood. This observation supports a proposition of using cancer-associated miRNAs as biomarkers for early cancer diagnosis (106). By evaluating specific exosomal miRNAs in 27 patients with lung adenocarcinoma, Rabinowits et al. (107) found that the mean concentrations of exosomes and miRNAs in exosomes varied significantly between cancer patients and normal controls, as opposed to an insignificance between miRNAs in exosomes and tumor tissues, indicating that the circulating exosomal miRNA might also be a useful diagnostic marker.

\section{MIRNAS AS NOVEL DRUG TARGETS FOR CANCER TREATMENT}

Distinct functions of miRNAs in tumor initiation, progression, and metastasis in human cancers strongly suggest miRNAs as novel drug targets or therapeutic tools to develop novel strategies for the treatment of human cancers. Plausible approaches could be through either downregulating "oncogenic" miRNAs or upregulating "tumor suppressor" miRNAs. Two approaches have been tested for inhibition of the levels of miRNAs, namely, short oligonucleotides complementary to miRNAs (antagomir or antimir) (108) and miRNA sponges, which refer to synthetic mRNAs containing multiple binding sites for a specific miRNA and thereby competitively sequestering the endogenous miRNA (109). To achieve efficient binding with a miRNA, antagomirs and antimirs can be chemically modified as 2-O-methyl oligoribonucleotides and locked nucleic acid (LNA), respectively (108). In contrast, elevating the level of endogenous miRNAs could be achieved by the delivery of synthetic miRNAs or DNA constructs that code for specific miRNAs.

Similar to other gene therapy approaches, efficient, safe, and tissue-specific delivery of synthetic miRNA, antagomir, or antimir has been tested in laboratories with certain degree of success. Delivery strategies include uses of plasmids, viral vectors or transposons, as well as cationic liposomes coupled with monoclonal antibodies to direct membrane-permeable reagents-conjugated miRNA to specific organs such as the lung and the liver. PC3 prostate cells express miR-221/222 at high levels. Treatment of mice bearing established subcutaneous PC3 tumor xenografts with anti-miR-221/222 antagomirs significantly suppressed tumor growth with a long-term effect of tumor reduction, suggesting the clinical applicability of antagomir (110). LNA-antimir oligonucleotides have also been tested in vitro as well as in vivo. Treatments with LNAantimirs against miR-16, miR-21, and the miR-17-92 cluster were tested in cancer cell lines derived from glioblastoma, colon cancers, breast cancers, and lung cancers (111). Administration of LNA-antimir to mice effectively blocks liver-specific miR-122 expression in vivo (112). Additionally, miR-127 is constitutively expressed in normal cells but epigenetically silenced in cancer cells. Treatment of cancer cells with chromatin-modifying drugs such as 5-Aza-CdR and PBA that inhibits DNA methylation significantly elevated the expression of miR-127 and inhibited cell proliferation, implicating an application of epigenetic approaches for cancer treatments (46).

\section{SUMMARY}

Investigation on the roles of miRNA in cancer represents a developing and promising research field in the war against cancer. As new knowledge and technologies continuously emerge, novel and effective anti-cancer strategies are becoming increasingly possible. Clinical management of human cancers will greatly benefit from the development of miRNA-based diagnostic and therapeutic approaches, and the pharmaceutical industry is also welcoming a new challenging opportunity in this exciting process. On the other hand, while the discovery of miRNA and the identification of its roles in cancer pathogenesis provide enormous promises in improving the outcome of cancer management, the research community as well as the industry face challenges in developing and delivering applicable and practically effective miRNA-based anti-cancer technologies. Like all other sequence specificity-based strategies, miRNA targeting can be accompanied by unwanted non-specific actions, and the resultant off-target effects could be even more daunting for miRNAs because miRNAs are characteristic of using imperfect complementarity to interact with their target sequences, displaying an intrinsic feature of the so-called multi-specificity. Furthermore, while the "multi-specific" feature enables a single miRNA to target more than one mRNA species, an individual mRNA can be synergistically regulated by multiple miRNA species. These features have obviously increased the complexity in developing effective miRNA-based anti-cancer approaches with minimal adverse effects. In addition, the development of new vehicle systems with low pharmacological toxicities is also urgently needed for the delivery of miRNAs or anti-miRNA inhibitors in vivo, particularly for systemic delivery. In this context, novel chemistry for miRNA modification, improved viral or non-viral vectors, and nanotechnology-based transportation tools are expected to find stages in the course of implementing safe and effective strategies for the detection and delivery of miRNAs.

Grant supports A Ministry of Science and Technology of China grant ([973]2005CB724605); a Natural Science Foundation of China grant (30872930); and a grant from the Science and Technology Department of the Zhuhai Municipality of Guangdong Province (PC20071076) to M.-F. Li; grants from the National Institutes of Health (CA102011, CA130966), American Cancer Society (RSG CSM-107144) and the Hillman Fellows Program for Innovative Cancer Research to S.-Y. Cheng. 


\section{REFERENCES}

1. Croce CM. Causes and consequences of microRNA dysregulation in cancer. Nat Rev Genet. 2009;10:704-14.

2. Garzon R, Calin GA, Croce CM. MicroRNAs in cancer. Annu Rev Med. 2009;60:167-79.

3. Lee RC, Feinbaum RL, Ambros V. The C. elegans heterochronic gene lin-4 encodes small RNAs with antisense complementarity to lin-14. Cell. 1993;75:843-54.

4. Esquela-Kerscherand A, Slack FJ. Oncomirs-microRNAs with a role in cancer. Nat Rev Cancer. 2006;6:259-69.

5. Selbach M, Schwanhausser B, Thierfelder N, Fang Z, Khanin R, Rajewsky N. Widespread changes in protein synthesis induced by microRNAs. Nature. 2008;455:58-63.

6. Petersen CP, Bordeleau ME, Pelletier J, Sharp PA. Short RNAs repress translation after initiation in mammalian cells. Mol Cell. 2006;21:533-42.

7. Liu J, Valencia-Sanchez MA, Hannon GJ, Parker R. MicroRNAdependent localization of targeted mRNAs to mammalian Pbodies. Nat Cell Biol. 2005;7:719-23.

8. Place RF, Li LC, Pookot D, Noonan EJ, Dahiya R. MicroRNA-373 induces expression of genes with complementary promoter sequences. Proc Natl Acad Sci U S A. 2008;105: 1608-13.

9. Li LC, Okino ST, Zhao H, Pookot D, Place RF, Urakami S et al. Small dsRNAs induce transcriptional activation in human cells. Proc Natl Acad Sci U S A. 2006;103:17337-42.

10. Lewis BP, Burge CB, Bartel DP. Conserved seed pairing, often flanked by adenosines, indicates that thousands of human genes are microRNA targets. Cell. 2005;120:15-20.

11. Calin GA, Dumitru CD, Shimizu M, Bichi R, Zupo S, Noch E et al. Frequent deletions and down-regulation of micro- RNA genes miR15 and miR16 at 13q14 in chronic lymphocytic leukemia. Proc Natl Acad Sci U S A. 2002;99:15524-9.

12. Takamizawa J, Konishi H, Yanagisawa K, Tomida S, Osada H, Endoh $\mathrm{H}$ et al. Reduced expression of the let-7 microRNAs in human lung cancers in association with shortened postoperative survival. Cancer Res. 2004;64:3753-6.

13. Aguda BD, Kim Y, Piper-Hunter MG, Friedman A, Marsh CB. MicroRNA regulation of a cancer network: consequences of the feedback loops involving miR-17-92, E2F, and Myc. Proc Natl Acad Sci U S A. 2008;105:19678-83.

14. Iorio MV, Casalini P, Tagliabue E, Menard S, Croce CM. MicroRNA profiling as a tool to understand prognosis, therapy response and resistance in breast cancer. Eur J Cancer. 2008;44:2753-9.

15. Kondo N, Toyama T, Sugiura H, Fujii Y, Yamashita H. miR-206 expression is down-regulated in estrogen receptor alpha-positive human breast cancer. Cancer Res. 2008;68:5004-8.

16. Gregory PA, Bert AG, Paterson EL, Barry SC, Tsykin A, Farshid G et al. The miR-200 family and miR-205 regulate epithelial to mesenchymal transition by targeting ZEB1 and SIP1. Nat Cell Biol. 2008;10:593-601.

17. Bhaumik D, Scott GK, Schokrpur S, Patil CK, Campisi J, Benz CC. Expression of microRNA-146 suppresses NF-kappaB activity with reduction of metastatic potential in breast cancer cells. Oncogene. 2008;28:5643-7.

18. Scott GK, Goga A, Bhaumik D, Berger CE, Sullivan CS, Benz CC. Coordinate suppression of ERBB2 and ERBB3 by enforced expression of micro-RNA miR-125a or miR-125b. J Biol Chem. 2007;282:1479-86.

19. Hossain A, Kuo MT, Saunders GF. Mir-17-5p regulates breast cancer cell proliferation by inhibiting translation of AIB1 mRNA. Mol Cell Biol. 2006;26:8191-201.

20. Valastyan S, Reinhardt F, Benaich N, Calogrias D, Szasz AM, Wang ZC et al. A pleiotropically acting microRNA, miR-31, inhibits breast cancer metastasis. Cell. 2009;137:1032-46.

21. Lehmann U, Hasemeier B, Christgen M, Muller M, Romermann $\mathrm{D}$, Langer $\mathrm{F}$ et al. Epigenetic inactivation of microRNA gene hsa-mir-9-1 in human breast cancer. J Pathol. 2008;214:17-24.

22. Webster RJ, Giles KM, Price KJ, Zhang PM, Mattick JS, Leedman PJ. Regulation of epidermal growth factor receptor signaling in human cancer cells by microRNA-7. J Biol Chem. 2009;284:5731-41.
23. Yu F, Yao $\mathrm{H}$, Zhu $\mathrm{P}$, Zhang $\mathrm{X}$, Pan Q, Gong $\mathrm{C}$ et al. let-7 regulates self renewal and tumorigenicity of breast cancer cells. Cell. 2007;131:1109-23.

24. Miller TE, Ghoshal K, Ramaswamy B, Roy S, Datta J, Shapiro CL et al. MicroRNA-221/222 confers tamoxifen resistance in breast cancer by targeting p27Kip1. J Biol Chem. 2008;283: 29897-903.

25. Camps C, Buffa FM, Colella S, Moore J, Sotiriou C, Sheldon H et al. hsa-miR-210 is induced by hypoxia and is an independent prognostic factor in breast cancer. Clin Cancer Res. 2008;14: 1340-8.

26. Kong W, Yang H, He L, Zhao JJ, Coppola D, Dalton WS et al. MicroRNA-155 is regulated by the transforming growth factor beta/Smad pathway and contributes to epithelial cell plasticity by targeting RhoA. Mol Cell Biol. 2008;28:6773-84.

27. Mertens-Talcott SU, Chintharlapalli S, Li X, Safe S. The oncogenic microRNA-27a targets genes that regulate specificity protein transcription factors and the G2-M checkpoint in MDAMB-231 breast cancer cells. Cancer Res. 2007;67:11001-11.

28. Pandeyand DP, Picard D. miR-22 inhibits estrogen signaling by directly targeting the estrogen receptor alpha mRNA. Mol Cell Biol. 2009;29:3783-90.

29. Zhu S, Si ML, Wu H, Mo YY. MicroRNA-21 targets the tumor suppressor gene tropomyosin 1 (TPM1). J Biol Chem. 2007;282:14328-36.

30. Ma L, Teruya-Feldstein J, Weinberg RA. Tumour invasion and metastasis initiated by microRNA-10b in breast cancer. Nature. 2007;449:682-8.

31. Huang Q, Gumireddy K, Schrier M, le Sage C, Nagel R, Nair S et al. The microRNAs miR-373 and miR-520c promote tumour invasion and metastasis. Nat Cell Biol. 2008;10:202-10.

32. Fulci V, Chiaretti S, Goldoni M, Azzalin G, Carucci N, Tavolaro $\mathrm{S}$ et al. Quantitative technologies establish a novel microRNA profile of chronic lymphocytic leukemia. Blood. 2007;109:494451.

33. Dijkstra MK, van Lom K, Tielemans D, Elstrodt F, Langerak AW, van 't Veer MB et al. 17p13/TP53 deletion in B-CLL patients is associated with microRNA-34a downregulation. Leukemia. 2009;23:625-7.

34. Stamatopoulos B, Meuleman N, Haibe-Kains B, Saussoy P, Van Den Neste E, Michaux L et al. microRNA-29c and microRNA223 down-regulation has in vivo significance in chronic lymphocytic leukemia and improves disease risk stratification. Blood. 2009:113:5237-45.

35. Pekarsky Y, Santanam U, Cimmino A, Palamarchuk A, Efanov $\mathrm{A}$, Maximov $\mathrm{V}$ et al. Tcl1 expression in chronic lymphocytic leukemia is regulated by miR-29 and miR-181. Cancer Res. 2006;66:11590-3.

36. Akao Y, Nakagawa Y, Kitade Y, Kinoshita T, Naoe T. Downregulation of microRNAs-143 and -145 in B-cell malignancies. Cancer Sci. 2007;98:1914-20.

37. Volinia S, Calin GA, Liu CG, Ambs S, Cimmino A, Petrocca F et al. A microRNA expression signature of human solid tumors defines cancer gene targets. Proc Natl Acad Sci U S A. 2006;103:2257-61.

38. Bandi N, Zbinden S, Gugger M, Arnold M, Kocher V, Hasan Let al. miR-15a and miR-16 are implicated in cell cycle regulation in a Rbdependent manner and are frequently deleted or down-regulated in non-small cell lung cancer. Cancer Res. 2009;69:5553-9.

39. Fabbri M, Garzon R, Cimmino A, Liu Z, Zanesi N, Callegari E et al. MicroRNA-29 family reverts aberrant methylation in lung cancer by targeting DNA methyltransferases 3A and 3B. Proc Natl Acad Sci U S A. 2007;104:15805-10.

40. Nasser MW, Datta J, Nuovo G, Kutay H, Motiwala T, Majumder $\mathrm{S}$ et al. Down-regulation of micro-RNA-1 (miR-1) in lung cancer. Suppression of tumorigenic property of lung cancer cells and their sensitization to doxorubicin-induced apoptosis by miR-1. J Biol Chem. 2008;283:33394-405.

41. Kluiver J, Poppema S, de Jong D, Blokzijl T, Harms G, Jacobs S et al. BIC and miR-155 are highly expressed in Hodgkin, primary mediastinal and diffuse large B cell lymphomas. J Pathol. 2005;207:243-9.

42. He L, Thomson JM, Hemann MT, Hernando-Monge E, Mu D, Goodson S et al. A microRNA polycistron as a potential human oncogene. Nature. 2005;435:828-33. 
43. Galardi S, Mercatelli N, Giorda E, Massalini S, Frajese GV, Ciafre SA et al. miR-221 and miR-222 expression affects the proliferation potential of human prostate carcinoma cell lines by targeting p27Kip1. J Biol Chem. 2007;282:23716-24.

44. Noonan EJ, Place RF, Pookot D, Basak S, Whitson JM, Hirata H et al. miR-449a targets HDAC-1 and induces growth arrest in prostate cancer. Oncogene. 2009;28:1714-24.

45. Bonci D, Coppola V, Musumeci M, Addario A, Giuffrida R, Memeo L et al. The miR-15a-miR-16-1 cluster controls prostate cancer by targeting multiple oncogenic activities. Nat Med. 2008;14:1271-7.

46. Saito Y, Liang G, Egger G, Friedman JM, Chuang JC, Coetzee GA et al. Specific activation of microRNA-127 with downregulation of the proto-oncogene BCL6 by chromatin-modifying drugs in human cancer cells. Cancer Cell. 2006;9:435-43.

47. Varambally S, Cao Q, Mani RS, Shankar S, Wang X, Ateeq B et al. Genomic loss of microRNA-101 leads to overexpression of histone methyltransferase EZH2 in cancer. Science. 2008;322: 1695-9.

48. Chan JA, Krichevsky AM, Kosik KS. MicroRNA-21 is an antiapoptotic factor in human glioblastoma cells. Cancer Res. 2005;65:6029-33.

49. Gilliesand JK, Lorimer IA. Regulation of p27Kip1 by miRNA 221/222 in glioblastoma. Cell Cycle. 2007;6:2005-9.

50. Wang Y, Lee AT, Ma JZ, Wang J, Ren J, Yang Y et al. Profiling microRNA expression in hepatocellular carcinoma reveals microRNA-224 up-regulation and apoptosis inhibitor-5 as a microRNA-224-specific target. J Biol Chem. 2008;283:13205-15.

51. Zhang X, Liu S, Hu T, Liu S, He Y, Sun S. Up-regulated microRNA-143 transcribed by nuclear factor kappa B enhances hepatocarcinoma metastasis by repressing fibronectin expression. Hepatology. 2009;50:490-9.

52. Connolly E, Melegari M, Landgraf P, Tchaikovskaya T, Tennant BC, Slagle BL et al. Elevated expression of the miR-17-92 polycistron and miR-21 in hepadnavirus-associated hepatocellular carcinoma contributes to the malignant phenotype. Am J Pathol. 2008;173:856-64.

53. Su H, Yang JR, Xu T, Huang J, Xu L, Yuan Y et al. MicroRNA-101, down-regulated in hepatocellular carcinoma, promotes apoptosis and suppresses tumorigenicity. Cancer Res. 2009;69:1135-42.

54. Datta J, Kutay H, Nasser MW, Nuovo GJ, Wang B, Majumder S et al. Methylation mediated silencing of microRNA-1 gene and its role in hepatocellular carcinogenesis. Cancer Res. 2008;68:5049-58.

55. Gramantieri L, Ferracin M, Fornari F, Veronese A, Sabbioni S, Liu CG et al. Cyclin G1 is a target of miR-122a, a microRNA frequently down-regulated in human hepatocellular carcinoma. Cancer Res. 2007;67:6092-9.

56. Grady WM, Parkin RK, Mitchell PS, Lee JH, Kim YH, Tsuchiya $\mathrm{KD}$ et al. Epigenetic silencing of the intronic microRNA hsamiR-342 and its host gene EVL in colorectal cancer. Oncogene. 2008;27:3880-8.

57. Tazawa H, Tsuchiya N, Izumiya M, Nakagama H. Tumorsuppressive miR-34a induces senescence-like growth arrest through modulation of the E2F pathway in human colon cancer cells. Proc Natl Acad Sci U S A. 2007;104:15472-7.

58. Toyota M, Suzuki H, Sasaki Y, Maruyama R, Imai K, Shinomura $\mathrm{Y}$ et al. Epigenetic silencing of microRNA-34b/c and B-cell translocation gene 4 is associated with $\mathrm{CpG}$ island methylation in colorectal cancer. Cancer Res. 2008;68:4123-32.

59. Slaby O, Svoboda M, Fabian P, Smerdova T, Knoflickova D, Bednarikova $\mathrm{M}$ et al. Altered expression of miR-21, miR-31, miR-143 and miR-145 is related to clinicopathologic features of colorectal cancer. Oncology. 2007;72:397-402.

60. Asangani IA, Rasheed SA, Nikolova DA, Leupold JH, Colburn NH, Post S et al. MicroRNA-21 (miR-21) post-transcriptionally downregulates tumor suppressor Pdcd4 and stimulates invasion, intravasation and metastasis in colorectal cancer. Oncogene. 2008;27:2128-36.

61. Liu T, Tang H, Lang Y, Liu M, Li X. MicroRNA-27a functions as an oncogene in gastric adenocarcinoma by targeting prohibitin. Cancer Lett. 2009;273:233-42.

62. Zhang Z, Li Z, Gao C, Chen P, Chen J, Liu W et al. miR-21 plays a pivotal role in gastric cancer pathogenesis and progression. Lab Invest. 2008;88:1358-66.
63. Takagi T, Iio A, Nakagawa Y, Naoe T, Tanigawa N, Akao Y. Decreased expression of microRNA-143 and -145 in human gastric cancers. Oncology. 2009;77:12-21.

64. Hu X, Macdonald DM, Huettner PC, Feng Z, El Naqa IM, Schwarz JK et al. A miR-200 microRNA cluster as prognostic marker in advanced ovarian cancer. Gynecol Oncol. 2009;114: 457-64.

65. Yang H, Kong W, He L, Zhao JJ, O'Donnell JD, Wang J et al. MicroRNA expression profiling in human ovarian cancer: miR214 induces cell survival and cisplatin resistance by targeting PTEN. Cancer Res. 2008;68:425-33.

66. Corney DC, Flesken-Nikitin A, Godwin AK, Wang W, Nikitin AY. MicroRNA-34b and MicroRNA-34c are targets of p53 and cooperate in control of cell proliferation and adhesion-independent growth. Cancer Res. 2007;67:8433-8.

67. Yan $\mathrm{D}$, Zhou X, Chen $\mathrm{X}, \mathrm{Hu} \mathrm{DN}$, Dong XD, Wang $\mathrm{J}$ et al. MicroRNA-34a inhibits uveal melanoma cell proliferation and migration through downregulation of c-Met. Invest Ophthalmol Vis Sci. 2009;50:1559-65.

68. Mullerand DW, Bosserhoff AK. Integrin beta 3 expression is regulated by let-7a miRNA in malignant melanoma. Oncogene. 2008;27:6698-706.

69. Felicetti F, Errico MC, Bottero L, Segnalini P, Stoppacciaro A, Biffoni $\mathrm{M}$ et al. The promyelocytic leukemia zinc finger-microRNA-221/-222 pathway controls melanoma progression through multiple oncogenic mechanisms. Cancer Res. 2008;68:2745-54.

70. Chang SS, Jiang WW, Smith I, Poeta LM, Begum S, Glazer C et al. MicroRNA alterations in head and neck squamous cell carcinoma. Int J Cancer. 2008;123:2791-7.

71. Liu X, Jiang L, Wang A, Yu J, Shi F, Zhou X. MicroRNA-138 suppresses invasion and promotes apoptosis in head and neck squamous cell carcinoma cell lines. Cancer Lett. 2009;286:217-22.

72. Childs G, Fazzari M, Kung G, Kawachi N, Brandwein-Gensler $\mathrm{M}, \mathrm{McLemore} \mathrm{M}$ et al. Low-level expression of microRNAs let$7 \mathrm{~d}$ and miR-205 are prognostic markers of head and neck squamous cell carcinoma. Am J Pathol. 2009;174:736-45.

73. O'Donnell KA, Wentzel EA, Zeller KI, Dang CV, Mendell JT. c-Myc-regulated microRNAs modulate E2F1 expression. Nature. 2005;435:839-43.

74. Sun F, Fu H, Liu Q, Tie Y, Zhu J, Xing R et al. Downregulation of CCND1 and CDK6 by miR-34a induces cell cycle arrest. FEBS Lett. 2008;582:1564-8.

75. Braun CJ, Zhang X, Savelyeva I, Wolff S, Moll UM, Schepeler T et al. p53-Responsive micrornas 192 and 215 are capable of inducing cell cycle arrest. Cancer Res. 2008;68:10094-104.

76. Silber J, Lim DA, Petritsch C, Persson AI, Maunakea AK, Yu M et al. miR-124 and miR-137 inhibit proliferation of glioblastoma multiforme cells and induce differentiation of brain tumor stem cells. BMC Med. 2008;6:14

77. Yu Z, Wang C, Wang M, Li Z, Casimiro MC, Liu M et al. A cyclin D1/microRNA $17 / 20$ regulatory feedback loop in control of breast cancer cell proliferation. J Cell Biol. 2008;182:509-17.

78. Leone G, DeGregori J, Sears R, Jakoi L, Nevins JR. Myc and Ras collaborate in inducing accumulation of active cyclin E/Cdk2 and E2F. Nature. 1997;387:422-6.

79. Egle A, Harris AW, Bouillet P, Cory S. Bim is a suppressor of Myc-induced mouse B cell leukemia. Proc Natl Acad Sci U S A. 2004;101:6164-9.

80. Sachdeva M, Zhu S, Wu F, Wu H, Walia V, Kumar S et al. p53 represses c-Myc through induction of the tumor suppressor miR145. Proc Natl Acad Sci U S A. 2009;106:3207-12.

81. Kong YW, Cannell IG, de Moor CH, Hill K, Garside PG, Hamilton TL et al. The mechanism of micro-RNA-mediated translation repression is determined by the promoter of the target gene. Proc Natl Acad Sci U S A. 2008;105:8866-71.

82. Kan T, Sato F, Ito T, Matsumura N, David S, Cheng Y et al. The miR-106b-25 polycistron, activated by genomic amplification, functions as an oncogene by suppressing p21 and Bim. Gastroenterology. 2009;136:1689-700.

83. Park SY, Lee JH, Ha M, Nam JW, Kim VN. miR-29 miRNAs activate $\mathrm{p} 53$ by targeting $\mathrm{p} 85$ alpha and CDC42. Nat Struct Mol Biol. 2009;16:23-9.

84. Raver-Shapira N, Marciano E, Meiri E, Spector Y, Rosenfeld N, Moskovits $\mathrm{N}$ et al. Transcriptional activation of miR-34a contributes to p53-mediated apoptosis. Mol Cell. 2007;26:731-43. 
85. Yamakuchi M, Ferlito M, Lowenstein CJ. miR-34a repression of SIRT1 regulates apoptosis. Proc Natl Acad Sci U S A. 2008;105:13421-6.

86. Choy EY, Siu KL, Kok KH, Lung RW, Tsang CM, To KF et al. An Epstein-Barr virus-encoded microRNA targets PUMA to promote host cell survival. J Exp Med. 2008;205:2551-60.

87. Jin WB, Wu FL, Kong D, Guo AG. HBV-encoded microRNA candidate and its target. Comput Biol Chem. 2007;31:124-6.

88. Wang S, Aurora AB, Johnson BA, Qi X, McAnally J, Hill JA et al. The endothelial-specific microRNA miR-126 governs vascular integrity and angiogenesis. Dev Cell. 2008;15:261-71.

89. Chenand Y, Gorski DH. Regulation of angiogenesis through a microRNA (miR-130a) that down-regulates antiangiogenic homeobox genes GAX and HOXA5. Blood. 2008;111:1217-26.

90. Wurdinger T, Tannous BA, Saydam O, Skog J, Grau S, Soutschek J et al. miR-296 regulates growth factor receptor overexpression in angiogenic endothelial cells. Cancer Cell. 2008;14:382-93.

91. Bracken CP, Gregory PA, Kolesnikoff N, Bert AG, Wang J, Shannon MF et al. A double-negative feedback loop between ZEB1-SIP1 and the microRNA-200 family regulates epithelialmesenchymal transition. Cancer Res. 2008;68:7846-54.

92. Hu Z, Chen J, Tian T, Zhou X, Gu H, Xu L et al. Genetic variants of miRNA sequences and non-small cell lung cancer survival. J Clin Invest. 2008;118:2600-8.

93. Jazdzewski K, Murray EL, Franssila K, Jarzab B, Schoenberg DR, de la Chapelle A. Common SNP in pre-miR-146a decreases mature miR expression and predisposes to papillary thyroid carcinoma. Proc Natl Acad Sci U S A. 2008;105:7269-74.

94. Jazdzewski K, Liyanarachchi S, Swierniak M, Pachucki J, Ringel MD, Jarzab B et al. Polymorphic mature microRNAs from passenger strand of pre-miR-146a contribute to thyroid cancer. Proc Natl Acad Sci U S A. 2009;106:1502-5.

95. Calin GA, Ferracin M, Cimmino A, Di Leva G, Shimizu M, Wojcik SE et al. A microRNA signature associated with prognosis and progression in chronic lymphocytic leukemia. N Engl J Med. 2005;353:1793-801.

96. Diederichsand S, Haber DA. Sequence variations of microRNAs in human cancer: alterations in predicted secondary structure do not affect processing. Cancer Res. 2006;66:6097-104.

97. Calin GA, Sevignani C, Dumitru CD, Hyslop T, Noch E, Yendamuri $\mathrm{S}$ et al. Human microRNA genes are frequently located at fragile sites and genomic regions involved in cancers. Proc Natl Acad Sci U S A. 2004;101:2999-3004.

98. Redon R, Ishikawa S, Fitch KR, Feuk L, Perry GH, Andrews TD et al. Global variation in copy number in the human genome. Nature. 2006;444:444-54.

99. Ouillette P, Erba H, Kujawski L, Kaminski M, Shedden K, Malek SN. Integrated genomic profiling of chronic lymphocytic leukemia identifies subtypes of deletion 13q14. Cancer Res. 2008;68:1012-21.

100. Xi Y, Shalgi R, Fodstad O, Pilpel Y, Ju J. Differentially regulated micro-RNAs and actively translated messenger RNA transcripts by tumor suppressor p53 in colon cancer. Clin Cancer Res. 2006;12:2014-24.

101. Melo SA, Ropero S, Moutinho C, Aaltonen LA, Yamamoto H, Calin GA et al. A TARBP2 mutation in human cancer impairs microRNA processing and DICER1 function. Nat Genet. 2009;41:365-70.

102. Chiosea S, Jelezcova E, Chandran U, Acquafondata M, McHale T, Sobol RW et al. Up-regulation of dicer, a component of the microRNA machinery, in prostate adenocarcinoma. Am J Pathol. 2006;169:1812-20.

103. Yanaihara N, Caplen N, Bowman E, Seike M, Kumamoto K, Yi $\mathrm{M}$ et al. Unique microRNA molecular profiles in lung cancer diagnosis and prognosis. Cancer Cell. 2006;9:189-98.

104. Yan LX, Huang XF, Shao Q, Huang MY, Deng L, Wu QL et al. MicroRNA miR-21 overexpression in human breast cancer is associated with advanced clinical stage, lymph node metastasis and patient poor prognosis. Rna. 2008;14:2348-60.

105. Lebanony D, Benjamin H, Gilad S, Ezagouri M, Dov A, Ashkenazi K et al. Diagnostic assay based on hsa-miR-205 expression distinguishes squamous from nonsquamous nonsmall-cell lung carcinoma. J Clin Oncol. 2009;27:2030-7.

106. Mitchell PS, Parkin RK, Kroh EM, Fritz BR, Wyman SK, Pogosova-Agadjanyan EL et al. Circulating microRNAs as stable blood-based markers for cancer detection. Proc Natl Acad Sci U S A. 2008;105:10513-8.

107. Rabinowits G, Gercel-Taylor C, Day JM, Taylor DD, Kloecker GH. Exosomal microRNA: a diagnostic marker for lung cancer. Clin Lung Cancer. 2009;10:42-6.

108. Krutzfeldt J, Rajewsky N, Braich R, Rajeev KG, Tuschl T, Manoharan $\mathrm{M}$ et al. Silencing of microRNAs in vivo with 'antagomirs'. Nature. 2005;438:685-9.

109. Ebert MS, Neilson JR, Sharp PA. MicroRNA sponges: competitive inhibitors of small RNAs in mammalian cells. Nat Methods. 2007;4:721-6.

110. Mercatelli N, Coppola V, Bonci D, Miele F, Costantini A, Guadagnoli $\mathrm{M}$ et al. The inhibition of the highly expressed miR221 and miR-222 impairs the growth of prostate carcinoma xenografts in mice. PLoS One. 2008;3:e4029.

111. Stenvang J, Silahtaroglu AN, Lindow M, Elmen J, Kauppinen S. The utility of LNA in microRNA-based cancer diagnostics and therapeutics. Semin Cancer Biol. 2008;18:89-102.

112. Elmen J, Lindow M, Schutz S, Lawrence M, Petri A, Obad S et al. LNA-mediated microRNA silencing in non-human primates. Nature. 2008;452:896-9. 